\title{
Cognitive Distortions and Self-Regulatory Personality Traits Associated with Proactive and Reactive Aggression in Early Adolescence
}

\author{
Sophieke Koolen • Astrid Poorthuis • \\ Marcel A. G. van Aken
}

Published online: 1 November 2011

(c) The Author(s) 2011. This article is published with open access at Springerlink.com

\begin{abstract}
This study investigated mechanisms behind proactive and reactive aggression, by examining whether four types of self-serving cognitive distortions and the personality traits agreeableness and conscientiousness differently predicted proactive and reactive aggression. Selfreport questionnaires and a peer nominations method were administered to 173 sixth grade children (age 10-13) of regular elementary schools in the Netherlands. Negative binomial regression analyses showed that proactive aggression was predicted by self-centered and disagreeable tendencies, whereas reactive aggression was predicted by the misattribution of blame to others and the self-regulatory aspects of agreeableness and conscientiousness. Findings emphasize the need to differentiate proactive and reactive aggression in order to accurately predict, prevent and treat aggressive behaviors in childhood.
\end{abstract}

Keywords Proactive aggression - Reactive aggression . Self-serving cognitive distortions - Agreeableness .

Conscientiousness

\section{Introduction}

Childhood aggression has repeatedly been associated with concurrent psychosocial maladjustment (Card and Little 2006), as well as with later externalizing problems (Vitaro

\section{S. Koolen $(\square)$}

Behavioural Science Institute, Radboud University Nijmegen, P.O. Box 9104, 6500 HE Nijmegen, The Netherlands e-mail: s.koolen@pwo.ru.nl

A. Poorthuis - M. A. G. van Aken

Department of Psychology, Utrecht University, Utrecht,

The Netherlands et al. 1998). In order to improve understanding, prediction and treatment of aggressive behaviors, subtypes of aggression have been defined. Often, a distinction is made between proactive and reactive aggression, based on the underlying function or motivation of the aggressive behavior. Proactive aggression is planned behavior that is unprovoked and used for instrumental gain or dominance over others (Dodge and Coie 1987). It is associated with social learning principles, because it is driven by positive outcome expectancies and controlled by its positive reinforcement. In contrast, reactive aggression occurs in reaction to a perceived or real threat or provocation (Dodge and Coie 1987). It is usually accompanied by anger and has its roots in the frustration-aggression hypothesis (Berkowitz 1989). Although both types of aggression can co-occur in the same child, research has shown that they are clearly distinct phenomena (Polman et al. 2007). There is extensive evidence showing proactive and reactive aggression to be associated with different etiological, expressive and persisting markers (e.g., Arsenio et al. 2009; Card and Little 2006; Smithmyer et al. 2000). The present study contributed to this research, by identifying social-cognitive processes and personality traits behind proactive and reactive aggression.

Social-Cognitive Processes in Proactive and Reactive Aggression

In addition to a well-documented role of (social-) cognitive factors in aggression (e.g., Arsenio and Lemerise 2004; Huesmann 1988; Huesmann and Guerra 1997), specifically for reactive and proactive aggression social-cognitive differences have been identified. In explaining the distinction between proactive and reactive aggression, an important role is assigned to social information processing (Crick and 
Dodge 1996). According to the social information processing model of Crick and Dodge (1994), a child's behavioral response to a social cue occurs as a result of six subsequent mental processing steps, including (1) encoding social cues, (2) interpreting social cues, (3) clarifying a goal, (4) constructing a response, (5) selecting a response and (6) enacting this response. It has been shown that proactive and reactive aggression are differently related to these steps of social information processing. Proactive aggression is associated with problems with the clarification of goals and the construction and selection of a response, whereas reactive aggression is related to difficulties with the encoding and interpretation of social cues (Crick and Dodge 1996).

Besides differences in social information processing patterns, moral, emotional and cognitive differences between reactive and proactive aggression have been identified. Research for instance shows that although reactive-aggressive children have difficulties judging social cues, they do seem to have a central moral value that intentionally harming others is not fair (Arsenio et al. 2009). In contrast, proactive-aggressive children appear disturbed in certain morally relevant values (Arsenio et al. 2009), and have positive outcome expectancies for aggression (e.g., Peets et al. 2011). Furthermore, whereas reactive-aggressive behavior is correlated with poor emotion regulation, proactive-aggressive behavior appears associated with so-called callous, unemotional traits (Marsee and Frick 2007).

Altogether, these results support the notion of distinct patterns of social information processing, moral reasoning and emotion processing in proactive and reactive aggression. Less is known, however, about the actual cognitions behind these behaviors. What thoughts or beliefs cause the child to decide that an aggressive response would be appropriate? Based on literature on general aggressive and antisocial behavior, the present study aimed to further disentangle cognitive processes underlying both aggressive functions focusing on specific distorted beliefs about aggression.

\section{Cognitive Distortions Associated with Proactive and Reactive Aggression}

Several studies on more general forms of aggression and antisocial behavior have focused on so-called self-serving cognitive distortions. Self-serving cognitive distortions are referred to as inaccurate or rationalizing beliefs, thoughts and attitudes (Barriga and Gibbs 1996). Both in delinquent and in non-delinquent adolescents and adults, the presence of these self-serving cognitive distortions has been associated with aggressive, offending, and antisocial behavior (e.g., Palmer 2003, 2005; Van der Velden et al. 2010). The cognitive distortions would facilitate aggression and provide aggressive individuals with justifications for their behavior, thereby contributing to its ongoing use (e.g., Barriga and Gibbs 1996). The often used four-category typology of self-serving cognitive distortions identifies four cognitive distortions, which are stated to be interrelated constructs (Barriga and Gibbs 1996). 'Self-centeredness' refers to the belief that one's own views, needs, rights and desires are so important that those of others are not taken fully into account or are even completely ignored. 'Minimizing/mislabeling' is the belief that antisocial behavior causes no real harm or is even admirable. 'Blaming others' describes the misattribution of blame for one's own antisocial behaviors to (innocent) outside sources. Finally, 'assuming the worst' is the attribution of hostile intentions to others and the expectation of worst-case scenarios (Barriga and Gibbs 1996).

Although this four-category typology describes the four cognitive distortions as interrelated constructs, it could be expected that some distortions are more important in proactive aggression, whereas others are more important in reactive aggression. Since proactive aggression is related to problems with clarification of goals and the construction and selection of a response (Crick and Dodge 1996), it could be assumed that these processing steps are based on self-serving beliefs that one's own interests are more important than those of others (self-centeredness) and that aggressive behavior causes no real harm or is even admirable (minimizing/mislabeling). Past research seems to support this last expectation; children engaging in proactive aggression have been found to value aggressive acts as more positive than children not engaging in proactive aggression (Crick and Dodge 1996).

In contrast, since reactive aggression is related to difficulties with the encoding and interpretation of social cues (Crick and Dodge 1996), it might be assumed that these difficulties in processing steps derive from the distorted assumptions that others have hostile intentions and that bad things will happen (assuming the worst). The first has been suggested by past research, showing that children engaging in reactive aggression tend to perceive hostility from others, even when no hostility was intended (Crick and Dodge 1996). This hostile attribution bias can be viewed as a component of the cognitive distortion assuming the worst. Furthermore, since reactive aggression results from a perceived or real threat or provocation, it could be expected that children engaging in reactive aggression justify their behavior by stating that others are to blame for it, even if these others actually are innocent (blaming others).

It has long been known that there is a bipolar dimension of overt-covert antisocial behavior, with overt behaviors consisting of confrontational acts and covert behaviors consisting of more concealed acts (Loeber and Schmaling 
1985). More recent research has shown that there is a high degree of behavior-specificity of cognitive distortions with respect to these overt and covert behavioral referents (Liau et al. 1998; Barriga et al. 2008). Overt-referential distortion relates to actual overt behavior but not to covert behavior, whereas covert-referential distortion relates to actual covert behavior but not to overt behavior. This distinction between cognitions about overt and covert antisocial behaviors seems particularly valuable when studying different distorted beliefs in proactive and reactive aggression. That is, given that reactive aggression and proactive aggression represent different aggressive functions (reactive, overt outbursts vs. deliberate and planned behavior), these aggressive behaviors might be associated with different underlying beliefs about overt versus covert antisocial behavior. Because proactive aggression is planned and unprovoked, these distorted thoughts probably concern both direct, confrontational behaviors, and calculated, nonconfrontational behaviors. Hence, proactive aggression was expected to be associated to 'self-centeredness' and 'minimizing/mislabeling' with respect to both overt and covert antisocial behaviors. In contrast, because reactive aggression is characterized by affective outbursts, it probably is associated with thoughts about direct, confrontational behaviors, but not with thoughts about indirect, more planned behaviors. Therefore, reactive aggression was proposed to be related to the cognitive distortions 'assuming the worst' and 'blaming others' with respect to overt, but not covert, antisocial behaviors.

\section{Personality Traits Associated with Proactive} and Reactive Aggression

When studying the relationship between cognitive distortions and proactive and reactive aggression, it is important to acknowledge that differences in social-cognitive functioning cannot fully account for different behavioral responses. Research has already shown that the relationship between cognitive functioning and general aggression or antisocial behavior is not similar for every individual, but rather depends on characteristics of the child. A common feature of these studies is their focus on person characteristics related to self-regulation (e.g., Fite et al. 2008; Meier and Robinson 2004). Therefore, the current study did not only focus on cognitive distortions, but also took into account such self-regulatory personality traits. Focus was on the personality traits agreeableness and conscientiousness, which have shown to both be core personality traits underlying self-regulation (Jensen-Campbell et al. 2002). It was chosen to focus on core, rather than surface, person characteristics (cf. Asendorpf and van Aken 2003), to clearly distinguish fundamental behavioral tendencies from cognitions and attributions. This enabled a clear investigation of the distinct roles of personality and cognitions in aggression.

Agreeableness is associated with inhibitory processes needed to control selfish, disagreeable tendencies (Ahadi and Rothbart 1994). When a child experiences tension between individual and social interests, agreeableness will lead to inhibition of selfish tendencies in favour of social concerns, because of the motivation to maintain positive relations with others (Graziano et al. 1996). This is supported by the finding that, although agreeable individuals do experience anger when confronted with a negative situation, this does not lead to aggressive behavioral responses (Jensen-Campbell et al. 2007). Proactiveaggressive tendencies to view aggression as an effective means to reach goals (Crick and Dodge 1996) seem to be in line with the selfish and hostile tendencies in disagreeable children (Graziano et al. 1996). Moreover, the finding that agreeableness affects the expression of experienced anger (Jensen-Campbell et al. 2007), suggests that low levels of agreeableness are related to aspects of reactive aggression, such as disinhibition of disagreeable responses when confronted with a provocation. Hence, both proactive and reactive aggression were expected to be related to agreeableness.

Conscientiousness also is related to several aspects of self-regulation, such as the ability to inhibit behaviors and the ability to persist in tasks. It has already been shown that anger is only related to aggression in individuals low on conscientiousness, suggesting that individuals with higher levels of conscientiousness are better able to regulate their behavior when they experience anger (Jensen-Campbell et al. 2007). Together, agreeableness and conscientiousness are personality traits that result from the temperamental precursor Effortful Control (EC), which describes children's capacities to plan behavior, focus and shift attention and suppress a dominant behavior to perform a subdominant response (Ahadi and Rothbart 1994). Low levels of conscientiousness might be related to characteristics of reactive aggression, such as deficiencies in the regulation of behavioral reactivity when confronted with a frustration. However, since proactive aggression is deliberate rather than provoked, it was assumed to be unrelated to behavioral control-processes of conscientiousness.

Furthermore, it was expected that these personality traits would affect the relationships between cognitive distortions and proactive and reactive aggression. Children who have higher levels of self-control may be less likely to engage in aggressive behaviors, even if their social-cognitions would 'put them at risk'. That is, self-centeredness and minimizing/mislabeling were expected to be related to proactive aggression, but only in children low on agreeableness. Blaming others and assuming the worst were 
thought to be related to reactive aggression, but only among children with low levels of agreeableness and conscientiousness.

\section{Summary of the Aims}

In short, the aims of the present study were twofold. The first research question focused on whether types of cognitive distortions were differently related to proactive and reactive aggression. The second research question examined whether agreeableness and conscientiousness were differently related to proactive and reactive aggression and whether the expected relationships between cognitive distortions and proactive and reactive aggression were dependent upon levels of conscientiousness and agreeableness.

In order to answer these research questions, children within the sixth grade of elementary school participated in the study. This was considered the most ideal age period for the measurements of the present study. The children had to be able to reflect on their cognitions and personality, and in addition peer pressure with respect to antisocial behavior has shown to increase in adolescence (e.g., Sim and Koh 2003). Data were collected crosssectionally, using self-reports and a peer nominations method.

\section{Methods}

\section{Participants}

The sample of this study consisted of 185 sixth grade children from nine classes of five regular elementary schools from the Netherlands. During data collection, 7 participants were absent. Of the remaining 178 children, 173 received parental consent ( $57.2 \%$ boys, $42.8 \%$ girls). Compared to the children in the final sample, the children who did not receive parental consent did not differ in their amount of nominations for proactive aggression $[t(176)=$ $.11, P=.91]$ and reactive aggression $[t(176)=1.16$, $P=.25]$. Similarly, absent children did not differ from their peers in their amount of nominations for proactive aggression $[t(178)=1.09, P=.28]$ and reactive aggression $[t(178)=.41, P=.69]$.

Participants were $10-13$ years old $(\mathrm{M}=11.7, \mathrm{SD}=.6)$. Both schools from small villages and larger cities from different regions of the Netherlands participated. The sample contained $71.1 \%$ children with parents born in the Netherlands, 6.9\% children with parents born in Turkey/ Morocco, 9.2\% children with parents born in Surinam/ the Antilles, and $12.7 \%$ children with parents born in other countries, thereby being representative of the Dutch population (Centraal Bureau voor de Statistiek [CBS] 2009).

Measurements

\section{Cognitive Distortions}

In order to measure the four cognitive distortions, the How I Think Questionnaire (HIT-Q), Dutch translation (Nas et al. 2008), was administered to all children. Psychometric properties of this questionnaire are satisfactory (Nas et al. 2008). Self-centeredness was measured with nine items, such as 'Getting what you need is the only important thing' (Cronbach's $\alpha=.74$ ). Minimizing/mislabeling was represented by nine items, including 'Only a coward would walk away from a fight' (Cronbach's $\alpha=.74$ ). Blaming others was measured with ten items, for example 'I lose my temper because people try to make me mad' (Cronbach's $\alpha=.72$ ). Assuming the worst was represented by eleven items, including 'You can't trust people because they will always lie to you' (Cronbach's $\alpha=.75$ ). Also, seven positive filler items were included to camouflage the items about cognitive distortions, such as 'Friends should be honest with each other'. The children rated all statements on a 6-point Likert scale, ranging from totally disagree to totally agree. Higher scores on the cognitive distortions indicated higher levels of cognitive distortions. ${ }^{1}$

In addition, the abovementioned scales could be divided into eight scales of the cognitive distortions in relation to overt and covert antisocial behavior. This resulted in four scales for overt behavior; self-centeredness-overt behavior (five items, Cronbach's $\alpha=.60$ ), minimizing/mislabelingovert behavior (four items, Cronbach's $\alpha=.55$ ), assuming the worst-overt behavior (six items, Cronbach's $\alpha=.64$ ), blaming others-overt behavior (five items, Cronbach's $\alpha=.59$ ), and four scales for covert behavior; self-centeredness-covert behavior (four items, Cronbach's $\alpha=.59$ ), minimizing/mislabeling-covert behavior (five items, Cronbach's $\alpha=.65$ ), assuming the worst-covert behavior (five items, Cronbach's $\alpha=.65$ ), blaming others-covert behavior (five items, Cronbach's $\alpha=.64$ ).

\footnotetext{
1 The questionnaire contained an additional scale to measure social desirability. The scale consisted of seven items, for instance 'I have sometimes said something bad about a friend' (Cronbach's $\alpha=.75$ ), where higher scores indicated lower levels of social desirability. To account for possible effects of social desirability on the results, two data files were composed; one with all participants and one without participants with a score on the anomalous response scale of the HIT$\mathrm{Q}$ below the cut-off value 2.75. All analyses were conducted with both data files. Since no differences in results were found, it was decided to use the complete data file, in order to obtain optimal power.
} 


\section{Agreeableness and Conscientiousness}

Agreeableness and conscientiousness were measured with the Big Five Inventory (BFI), Dutch translation (Denissen et al. 2008), which has shown to be a psychometrically valid questionnaire. Agreeableness was represented by nine items, for instance 'I see myself as someone who is considerate and kind to almost everyone' (Cronbach's $\alpha=.63$ ). Conscientiousness was measured with nine items, such as 'I see myself as someone who makes plans and follows through with them' (Cronbach's $\alpha=.72$ ). Children were asked to rate their agreement with the statements on a 5-point Likert scale, ranging from strongly disagree to strongly agree. Items with a reversed score were recoded, after which mean scores on the items of the two scales were calculated. Higher scores indicated higher levels of agreeableness and conscientiousness.

\section{Proactive and Reactive Aggression}

Nominations for Five Functions of Aggression The dependent variables proactive and reactive aggression were assessed through peer nominations, using the peer nominations version of the teacher-report Instrument for Reactive and Proactive Aggression (IRPA; Polman et al. 2008). Peer nominations have been shown to be a reliable measure for aggressive behaviors (Dodge and Coie 1987). Four questions were asked about four types of aggressive behavior, including 'Which children kick, hit or push other children?' (physical aggression), 'Which children call other children names?' (verbal aggression), 'Which children gossip or tell lies about other children?' (relational aggression), and 'Which children do sneaky things that are not allowed?' (covert aggression). For every question, the children could nominate up to five classmates, although this was not obligatory. After having nominated a classmate, the children had to choose the function of the aggressive behavior from a list of five functions: e.g., 'If...calls someone names, why does he/she do that? Because he/she (1) is angry, (2) is being bullied, (3) wants to be mean, (4) wants to reach his/her goal, (5) wants to be the boss'. Multiple functions could be chosen, meaning that a child could be nominated for a reactive and a proactive function simultaneously for the same aggressive behavior. For every child, the received nominations were counted per function. According to the IRPA, the reactive aggression scale consists of functions one and two, whereas the proactive aggression scale consists of functions three, four and five. However, principal component analysis on the current data showed that, within the present sample, this specific distinction was not found. The rotated factor solution demonstrated the existence of two factors (factors with Eigenvalues $>1$ ), together accounting for $76.52 \%$ of the variability in the original five variables. Within this two-factor solution, 'bullied' loaded
Table 1 Factor loadings of the five functions of aggression on the two factors resulting from the principal component analysis

\begin{tabular}{lll}
\hline & $\begin{array}{l}\text { Factor 1 (proactive } \\
\text { aggression) }\end{array}$ & $\begin{array}{l}\text { Factor 2 (reactive } \\
\text { aggression) }\end{array}$ \\
\hline Being angry & .63 & .41 \\
Being bullied & .04 & .96 \\
Wanting to be mean & .88 & .14 \\
Wanting to reach a goal & .88 & .09 \\
Wanting to be the boss & .88 & -.08 \\
\hline
\end{tabular}

Received nominations of proactive and reactive aggression were corrected for class size

high on one factor, whereas 'mean', 'goal' and 'boss' loaded high on the other factor. Yet, 'angry' loaded on both factors (Table 1). Therefore, it was decided to exclude the 'angry' function from the analysis.

Nominations for Proactive and Reactive Aggression For every child, the received nominations for reactive and proactive aggression were counted. This was done for all four questions of aggression (physical, verbal, relational, covert aggression) separately. For reactive aggression, a child received a 1 -score when being nominated by a classmate for the reactive function (bullied). Similarly, for proactive aggression, a child received a 1-score when being nominated by a classmate for one or more of the proactive functions (mean, goal, boss). The nominations the child received from all classmates for proactive and reactive aggression were summed across all four questions of aggression, resulting in two scales of proactive and reactive aggression, with scores possibly ranging from 0 to 4 times the size of the class. Influence of class size was corrected for during the actual data analysis. Children with higher scores on the variables proactive and reactive aggression were nominated more often by their classmates on these types of aggression, as compared to children with lower scores on these variables.

\section{Procedure}

The questionnaires were administered in the classroom to all children simultaneously, during school hours. Instructions were read out loud. It was explained that there were no right or wrong answers and confidentiality was emphasized. The children completed the BFI, HIT-Q and the peer nominations consecutively. Duration of the procedure was $1 \mathrm{~h}$ on average.

\section{Data Analysis}

It was intended to conduct a multiple regression analysis, for which model assumptions were checked, according to the criteria derived from Tabachnick and Fidell (2007). 
Yet, results showed that proactive and reactive aggression were both severely positively skewed and could not be transformed. Therefore, instead of being analyzed as normal continuous variables, they were interpreted as rate data. Rate data represent a discrete probability distribution, where the rate is a count of events occurring to a particular participant, divided by some measure of that participant's exposure to the event (Agresti 2002). In the present study, the rate was the number (count) of received nominations for proactive or reactive aggression occurring to a particular child, divided by that child's exposure to receiving nominations, that is, the size of the class. In order to analyze these rate data, negative binomial regression analyses were conducted (Agresti 2002). ${ }^{2}$ Results were expressed as odds ratios. Scores on cognitive distortions and personality traits were used to predict a child's odds of receiving a nomination for reactive or proactive aggression, when taking into account the size of the class. An alpha level of .05 was used for all statistical analyses.

Negative binomial regression analyses were performed for the dependent variables proactive and reactive aggression and the independent variables (a) the four cognitive distortions, (b) overt and covert subtypes of the cognitive distortions, and (c) agreeableness and conscientiousness. In addition, separate negative binomial regression analyses were performed for possible interaction effects among cognitive distortions and personality traits. Both the scores on the cognitive distortions and the scores on the personality traits were centered, to avoid multicollinearity problems (Tabachnick and Fidell 2007).

\section{Results}

\section{Descriptive Analysis}

Table 2 presents the scale means, standard deviations and the range of the cognitive distortions and the personality traits. Of the 173 children, 116 children were nominated for

\footnotetext{
2 Although a Poisson regression is the standard method to model rate data, the present data showed overdispersion, indicating that the observed variances were larger than the means $(M=5.08$, $\sigma^{2}=72.88$ for proactive aggression and $M=.50, \sigma^{2}=1.03$ for reactive aggression). Because Poisson's assumption of equidispersion (the variance being equal to its mean) was violated, a negative binomial model was chosen, which models overdispersed Poisson data. Since the possibility of being nominated depended upon of number of children in the class, the differences in class size (differences in the exposure to the nominations) needed to be controlled for. In negative binomial regression this is handled as an offset (the natural logarithm of class size-1). The offset was included as a predictor variable in the model, but was differentiated from other variables by being analyzed as a constant (forced to have a coefficient 1) and therefore being independent of scores of other predictor variables (Agresti 2002).
}

Table 2 Descriptive statistics of study variables

\begin{tabular}{llll}
\hline & M & SD & Range \\
\hline Self-centeredness & 2.36 & .78 & $1.00-5.44$ \\
Overt & 1.99 & .77 & $1.00-5.00$ \\
Covert & 2.81 & 1.03 & $1.00-5.00$ \\
Minimizing harm & 2.24 & .72 & $1.00-4.56$ \\
Overt & 2.53 & .89 & $1.00-5.50$ \\
Covert & 2.02 & .75 & $1.00-5.00$ \\
Blaming others & 2.43 & .75 & $1.00-5.10$ \\
Overt & 2.50 & .96 & $1.00-5.50$ \\
Covert & 2.36 & .82 & $1.00-5.40$ \\
Assuming the worst & 2.19 & .68 & $1.00-5.00$ \\
Overt & 2.55 & .83 & $1.00-5.33$ \\
Covert & 1.77 & .71 & $1.00-4.60$ \\
Conscientiousness & 3.38 & .66 & $1.22-4.78$ \\
Agreeableness & 3.76 & .56 & $1.89-4.78$ \\
\hline
\end{tabular}

The four scales of the cognitive distortions were divided into eight subscales for the particular distortions in relation to overt and covert antisocial behavior

proactive aggression once or more, whereby per question the children were nominated by $0-75 \%$ of the classmates. For reactive aggression, 49 children were nominated once or more, whereby per question the children were nominated by $0-18.18 \%$ of the classmates. Furthermore, correlational analyses were conducted to examine overall patterns among variables (Table 3). The cognitive distortions appeared to be strongly, positively correlated, indicating that higher scores on one cognitive distortion were related to higher scores on another cognitive distortion. The personality traits agreeableness and conscientiousness were moderately, positively correlated, indicating higher levels of agreeableness to be related to higher levels of conscientiousness. Agreeableness correlated negatively with the four cognitive distortions and proactive and reactive aggression, whereas conscientiousness was mostly unrelated to these variables. Finally, there appeared to be a weak, positive correlation between reactive and proactive aggression; increased nominations on one type of aggression were associated with elevated nominations on the other type of aggression. Yet, this correlation was much weaker than was found in most previous studies on proactive and reactive aggression (Polman et al. 2007). In order to control for this correlation, during all main analyses proactive aggression was added to the baseline model when predicting reactive aggression, and vice versa.

Next, it was examined whether demographic characteristics were significant predictors of proactive and reactive aggression. Gender appeared to be a significant predictor both of proactive aggression $(\beta=.63, P=.01)$, and of reactive aggression $(\beta=.50, P=.06)$. As compared to 
Table 3 Intercorrelations among study variables

\begin{tabular}{|c|c|c|c|c|c|c|c|c|}
\hline & 1 & 2 & 3 & 4 & 5 & 6 & 7 & 8 \\
\hline 1. Self-centeredness & 1.00 & & & & & & & \\
\hline 2. Minimizing & $.72 * * *$ & 1.00 & & & & & & \\
\hline 3. Blaming others & $.67 * * *$ & $.71 * * *$ & 1.00 & & & & & \\
\hline 4. Assuming the worst & $.69 * * *$ & $.74 * * *$ & $.74 * * *$ & 1.00 & & & & \\
\hline 5. Conscientiousness & $-.19^{*}$ & -.15 & -.13 & $-.19 *$ & 1.00 & & & \\
\hline 6. Agreeableness & $-.38 * * *$ & $-.38 * * *$ & $-.46 * * *$ & $-.45^{* * *}$ & $.36 * * *$ & 1.00 & & \\
\hline 7. Proactive aggression & $.23 * *$ & $.17 *$ & $.20 * *$ & $.17 *$ & -.05 & $-.31 * *$ & 1.00 & \\
\hline 8. Reactive aggression & $.23 * *$ & $.23 * *$ & $.27 * * *$ & $.25 * * *$ & -.10 & $-.17 *$ & $.17 *$ & 1.00 \\
\hline
\end{tabular}

Received nominations of proactive and reactive aggression were corrected for class size

$* P<.05$

$* * P<.01$

*** $P<.001$

girls, boys were 1.88 and 1.65 times as likely to become nominated for proactive aggression and reactive aggression, respectively. Furthermore, although ethnicity did not predict reactive aggression $(\beta=.37, P=.16)$, ethnicity appeared to be a significant predictor of proactive aggression $(\beta=.96, P=.01)$, with children with parents not born in the Netherlands being 2.61 times as likely to become nominated for proactive aggression as compared to children with parents born in the Netherlands. Based on these results, it was decided to control for gender and ethnicity during all main analyses.

Cognitive Distortions Associated with Proactive and Reactive Aggression

\section{Proactive Aggression}

First, it was analyzed whether the four cognitive distortions could predict proactive aggression (Model 1, Table 4). In line with the hypothesis, self-centeredness was a positive predictor of the probability of being nominated for proactive aggression, when controlling for the other cognitive distortions. For an increase of one point on the scores of self-centeredness, the odds of becoming nominated for proactive aggression increased with 62\%. Although hypothesized, minimizing/mislabeling did not predict proactive aggression. As was expected, blaming others and assuming the worst did not predict proactive aggression.

Next, a distinction was made between cognitive distortions about overt antisocial behavior and covert antisocial behavior (Model 2, Table 4). Again, when controlling for the others distortions, results demonstrated that self-centered cognitive distortions about overt antisocial behavior were a significant positive predictor. For a one unit increase in self-centeredness with respect to overt behavior, the odds of becoming nominated for proactive aggression increased with approximately $60 \%$. Other types of distorted thoughts about overt and covert antisocial behavior did not predict the probability of being nominated for proactive aggression.

In conclusion, although self-centeredness and minimizing/mislabeling with respect to overt and covert antisocial behaviors were expected to predict proactive aggression, only self-centeredness about overt (not covert) behaviors appeared to be an important predictor. As expected, blaming others and assuming the worst were unrelated to nominations of proactive aggression.

\section{Reactive Aggression}

Second, it was analyzed whether the four cognitive distortions could predict the odds of being nominated for reactive aggression (Model 1, Table 4). Although it was expected that blaming others and assuming the worst would be related to reactive aggression, none of the cognitive distortions could predict reactive aggression when controlling for the other distortions.

As for proactive aggression, additional analyses were conducted with the cognitive distortions in reference to overt versus covert antisocial behaviors (Model 2, Table 4). Findings demonstrated that, although blaming others in general was unpredictive of reactive aggression, blaming others for overt antisocial behavior was a positive predictor of reactive aggression, when controlling for the other cognitive distortions. For one point increase in blaming others for overt antisocial behavior, the odds of being nominated for reactive aggression increased with $46 \%$. Other distorted thoughts about overt and covert antisocial behavior were unrelated to reactive aggression.

These findings partly confirmed the expectations. Although, both blaming others and assuming the worst were hypothesized to predict reactive aggression, only blaming others with respect to overt antisocial behavior appeared to be a significant predictor. As expected, reactive 
Table 4 Estimates resulting from the prediction of proactive aggression and reactive aggression by cognitive distortions and personality traits

\begin{tabular}{|c|c|c|c|c|c|c|c|c|}
\hline & \multicolumn{4}{|c|}{ Proactive aggression } & \multicolumn{4}{|c|}{ Reactive aggression } \\
\hline & $\beta$ & SE & $\operatorname{Exp}(\beta)$ & $P$ value & $\beta$ & SE & $\operatorname{Exp}(\beta)$ & $P$ value \\
\hline \multicolumn{9}{|l|}{ Model 1} \\
\hline Self-centeredness & .48 & .23 & 1.62 & .03 & .11 & .26 & 1.12 & .68 \\
\hline Minimizing & .10 & .26 & 1.11 & .71 & .02 & .29 & 1.02 & .95 \\
\hline Blaming others & -.10 & .26 & .90 & .70 & .29 & .27 & 1.34 & .28 \\
\hline Assuming the worst & -.19 & .29 & .83 & .51 & .24 & .28 & 1.27 & .39 \\
\hline \multicolumn{9}{|l|}{ Model 2} \\
\hline Overt-self-centeredness & .47 & .23 & 1.60 & .04 & -.15 & .26 & .86 & .58 \\
\hline Overt-minimizing & .03 & .19 & 1.03 & .88 & .15 & .20 & 1.16 & .44 \\
\hline Overt-blaming others & .05 & .16 & 1.05 & .75 & .38 & .19 & 1.46 & .04 \\
\hline Overt-assuming the worst & -.02 & .22 & .98 & .92 & -.08 & .21 & .92 & .69 \\
\hline Covert-self-centeredness & .08 & .15 & 1.08 & .56 & .16 & .18 & 1.17 & .35 \\
\hline Covert-minimizing & .12 & .24 & 1.13 & .63 & -.05 & .24 & .95 & .82 \\
\hline Covert-blaming others & -.17 & .20 & .84 & .40 & -.13 & .21 & .88 & .52 \\
\hline Covert-assuming the worst & -.28 & .26 & .76 & .29 & .36 & .25 & 1.43 & .15 \\
\hline \multicolumn{9}{|l|}{ Model 3} \\
\hline Agreeableness (shared + unique) & -.73 & .22 & .48 & .00 & -.42 & .23 & .66 & .05 \\
\hline \multicolumn{9}{|l|}{ Model 4} \\
\hline Conscientiousness (shared + unique) & -.15 & .17 & .86 & .39 & -.36 & .19 & .70 & .06 \\
\hline \multicolumn{9}{|l|}{ Model 5} \\
\hline Agreeableness (unique) & -.80 & .24 & .45 & .00 & -.28 & .26 & .76 & .28 \\
\hline Conscientiousness (unique) & .13 & .19 & 1.14 & .49 & -.26 & .21 & .77 & .23 \\
\hline
\end{tabular}

Reactive aggression was added to the model when predicting proactive aggression. Proactive aggression was added to the model when predicting reactive aggression. Results from the negative binomial regression analyses were expressed as coefficient $\beta$. $\operatorname{Exp}(\beta)$ was interpreted in terms of odds ratios. The formula $100[\operatorname{Exp}(\beta)-1]$ provided the percentage change in number of peer nominations for each unit increase in the predictor variable (Agresti 2002)

aggression was not predicted by self-centeredness and minimizing/mislabeling.

Personality Traits Associated with Proactive and Reactive Aggression

Although being separate constructs, agreeableness and conscientiousness together serve a self-regulatory function (Jensen-Campbell et al. 2007). Therefore, they were examined with and without taking into account their shared variances. Both models showed that agreeableness was a significant negative predictor of the probability of being nominated for proactive aggression, whereas conscientiousness was unrelated to proactive aggression (Table 4). If a child's score on agreeableness increased with one point, the odds of being nominated for proactive aggression decreased with approximately $55 \%$ for a one unit increase in agreeableness. These findings confirmed the expectations; agreeableness, but not conscientiousness, was negatively related to proactive aggression.

For reactive aggression, both agreeableness and conscientiousness were (marginally) significant negative predictors when not taking into account the overlap among both personality traits (Models 3 and 4, Table 4). Children with higher levels of agreeableness and conscientiousness were less likely to become nominated for reactive aggression, as compared to children with lower levels of these personality traits. Yet, when controlling for the shared variances, neither agreeableness nor conscientiousness were significant predictors (Model 5, Table 4). Although it was hypothesized that both traits would predict reactive aggression, this was only found when shared variances were part of the prediction.

Besides these main effects, interactions among the cognitive distortions and agreeableness and conscientiousness were expected. However, no significant interaction effects were found.

\section{Discussion}

This study aimed to further explore the mechanisms behind proactive and reactive aggression. First, it was examined whether proactive and reactive aggression were differently 
predicted by cognitive distortions. As was expected, proactive aggression was predicted by self-centeredness about overt behaviors, but not by blaming others and assuming the worst. In contrast to the hypothesis, minimizing/mislabeling was unrelated to proactive aggression. Reactive aggression was predicted by blaming others about overt behaviors, but not by self-centeredness and minimizing/ mislabeling, which confirmed the hypothesis. However, assuming the worst was not associated with reactive aggression. Second, it was explored whether proactive and reactive aggression were differently predicted by the personality traits agreeableness and conscientiousness and whether these traits moderated the relationships between the cognitive distortions and proactive and reactive aggression. As was hypothesized, proactive aggression was predicted by agreeableness, but not by conscientiousness. Although, reactive aggression was expected to be associated with both personality traits, agreeableness and conscientiousness only were significant predictors when not controlling for the overlap among both traits. In contrast to the expectations, agreeableness and conscientiousness did not moderate the associations between the distortions and proactive and reactive aggression. Taken this together, present results were in line with previous findings that proactive aggression and reactive aggression are two distinct types of aggression with different underlying markers (e.g., Polman et al. 2007). Although, the behavioral expressions are similar, they serve different functions and are driven by different social-cognitive processes and personality traits.

It was found that proactive aggression is predicted by the self-centered belief that one's own interests and needs are more important than those of others. Possibly, when encountering a social situation, this egocentric bias promotes selection of selfish goals and subsequent aggressive responses to reach these goals. Because aggression is likely to lead to the desired outcome, the positive view of aggression as a means to fulfil egocentric goals may become reinforced and therefore strengthen over time. This is in line with social learning principles associated with proactive aggression, which state that proactive aggression is driven by positive outcome expectancies and is controlled by its reinforcements (Dodge and Coie 1987). It should be noted however, that the prediction of proactive aggression by self-centeredness only holds when the egocentric beliefs refer to overt antisocial behaviors (e.g., 'You should get what you need, even if it means someone has to get hurt'), not covert behaviors (e.g., 'If I see something I like, I take it'). Since proactive aggression is planned and unprovoked, it was expected that children engaging in proactive aggression would apply their egocentric bias to thoughts about overt, confrontational as well as covert, more calculated behaviors. As research has already shown a high degree of cognition-behavior specificity (Barriga et al. 2008), the fact that no cognitive distortions about this type of behaviors were found might be explained by the fact that overt behaviors such as physical aggression are relatively common, whereas covert behaviors such as stealing might be rare within this nonclinical sample.

Besides this role of self-centeredness, it was expected that the belief that antisocial behavior causes no real harm and is acceptable (minimizing/mislabeling) would contribute to proactive aggressive behaviors as well. However, this was not supported by the present results. Perhaps these 'typical' children know that aggressive behavior generally is not acceptable (low score on minimizing/mislabeling). Yet, only when it serves their own needs, they think it is justified (high score on self-centeredness).

Based on previous studies that have found moderating effects of characteristics of self-control on the relation between social-cognitive processes and aggression, it was expected that the association between self-centeredness and proactive aggression would be dependent upon a child's level of agreeableness. However, this was not supported by the current findings. Both children who are more disagreeable and children who are more self-centered engage in proactive aggression more often as compared to less disagreeable and less self-centered children. Also, children who are more disagreeable tend to have more selfcentered thoughts. However, proactive aggression is predicted by self-centeredness regardless of a child's level of agreeableness, and vice versa.

In contrast to proactive aggression, reactive aggression has previously been associated with problems with the encoding and the interpretation of social cues (Crick and Dodge 1996). Surprisingly, the expectation that assuming worst case scenarios and hostile intentions from others would predict reactive aggression was not confirmed by the present study. This might be explained by the present measurement of reactive aggression. Due to validity problems with one of the items for reactive aggression, the definition of reactive aggression was restricted to 'aggression in reaction to being bullied'. This implies that the behavior is a result of a child's actual victimization, not just a child's expectation or perception of threat. The child could not misinterpret the situation as threatening, because he or she was truly victimized, as was observed by peers. Yet, assuming the worst might be involved in reactive aggression based on perceived rather than actual threat, because biased assumptions probably only affect interpretations and subsequent behavior in ambiguous or neutral situations, but not in situations where one is clearly being bullied.

As was expected, reactive aggression was predicted by thoughts of blaming others in reference to overt (e.g., 'I lose my temper because people try to make me mad'), not 
covert (e.g., 'People force me to lie when they ask me too many questions'), antisocial behaviors. The reactiveaggressive anger probably is expressed through overt, primitive behaviors such as physical aggression, rather than through covert, nonconfrontational behaviors such as lying or stealing. Since distortions are behavior-specific (Barriga et al. 2008), it seems not surprising that they only refer to overt antisocial behaviors. Yet, these findings have to be replicated in clinical samples, because the null-finding of distortions related to covert antisocial behaviors could also reflect the absence of such indirect conduct-disordered type of behaviors within the present sample.

Besides this cognitive distortion, agreeableness and conscientiousness were also expected to play a role in reactive aggression. Interestingly, findings showed that only the combined effect of conscientiousness and agreeableness was important for reactive aggression. As described earlier, agreeableness and conscientiousness are considered to result from the temperamental precursor EC, which fulfils a self-regulatory function (Ahadi and Rothbart 1994). Agreeableness is important in the regulation of frustration coming from others (e.g., inhibition of disagreeable tendencies), whereas conscientiousness is important in the regulation of frustration coming from tasks (e.g., inhibition of certain behaviors in favour of others) (Caspi and Shiner 2006). It seems this self-regulatory aspect that determines whether a reactive-aggressive reaction can be suppressed to perform a more appropriate response, rather than the unique characteristics of both traits. Since agreeableness and conscientiousness were no unique predictors of reactive aggression, there were no moderating functions of self-regulatory person characteristics on the association between social-cognitions and aggression.

This study has some important theoretical and practical implications. The identification of distinctive cognitive distortions underlying both types of aggression not only supports previous findings that social information is processed differently, but extends this literature by revealing why the information is processed differently, thereby contributing to what is referred to by social information processing theorists as the identification of 'latent knowledge constructs' (Dodge and Rabiner 2004) underlying both types of aggression. Moreover, associated self-regulatory personality traits have been found to differ as well. These findings reaffirm the need to differentiate aggressive behaviors based on their functions. Instead of there being one general mindset related to aggression, different cognitive distortions and self-regulatory traits predict different types of aggression. This detailed information should help improve the formulation of different goals and guidelines for educational programs and cognitive therapy for proactive and reactive aggression.
An important additional implication for research specifically on self-serving cognitive distortions is the finding that different distortions differently relate to types of problem behavior. Until now, the four distortions are examined as interrelated constructs. Yet, the present study showed that they can occur in one person independently from each other. This should be acknowledged when studying self-serving cognitive distortions.

One limitation of this study is the fact that the design does not allow to infer causation. Although, cognitions and personality in general are said to drive behavior, previous experiences and behaviors can also affect cognitions. This however, can not be concluded from the current findings and should be studied by future research. Furthermore, the results only apply to aggression in a nonclinical sample. Nonetheless, since even within a nonclinical sample distinctive patterns among proactive and reactive aggression have been found, it could be suggested that these differences will even be more pronounced within a clinical sample. However, it does seem worthwhile to actually study associations between distortions with respect to covert antisocial behaviors and proactive and reactive aggression within a clinical sample. Another limitation regards the low reliabilities of the eight subscales measuring the overt and covert cognitive distortions, which was probably due to the limited amount of items covering each subscale. Yet, despite this, it was chosen to use the subscales, in order to further discern the different types of cognitive distortions, providing a more nuanced view of the relationship between cognitions and proactive and reactive aggression. Finally, the measurement of reactive aggression was restricted. Although, an existing questionnaire was used, one item for reactive aggression had to be removed from the analyses, which resulted in a restricted definition of reactive aggression ('a reaction to being bullied'). Interestingly however, the degree of association among both types of aggression was much weaker than in previous studies (Polman et al. 2007), indicating that proactive and reactive aggression were now distinguished more effectively. Possibly, reactive aggression is differentiated better from proactive aggression when the definition includes aggression only as a result of a true provocation, as compared with broader definitions that also include for example aggression in anticipation to a perceived threat. Future research should further explore this possibility.

Strength of the present study is the fact that the sample consisted of children from different areas and schools within the Netherlands. Demographic statistics such as ethnicity showed that the sample was highly representative of children within the Dutch population. Another strength is the use of different reporters for different measures. Especially for sensitive topics such as aggression and 
cognitive distortions, the use of same reporters for all measures can lead to artificial associations, due to shared method variance. This risk of confounded reports has been minimized, by using self-reports for cognitive and personality measures, but peer nominations for the behavioral aggression measures. Peer nominations have been shown to be an appropriate method for measuring aggressive behaviors, since observations of the same behavior are provided by many different informants. No single informant can extremely affect a child's final score (Huesmann et al. 1994).

In conclusion, the current study differentiated proactive and reactive aggression based on cognitive distortions and self-regulatory personality traits. Overall, the findings suggest that proactive aggression is predicted by egocentric and disagreeable tendencies, whereas reactive aggression is predicted by poor self-regulation and the misattribution of blame to others. This emphasizes the need to differentiate aggression on basis of its function. Specification of different programs and interventions based on these differences is important.

Open Access This article is distributed under the terms of the Creative Commons Attribution Noncommercial License which permits any noncommercial use, distribution, and reproduction in any medium, provided the original author(s) and source are credited.

\section{References}

Agresti, A. (2002). Categorical data analysis (2nd ed.). New York: Wiley.

Ahadi, S. A., \& Rothbart, M. K. (1994). Temperament, development and the Big Five. In C. F. Halverson, G. A. Kohnstamm, \& R. P. Martin (Eds.), The developing structure of temperament and personality from infancy to adulthood (pp. 186-207). Hillsdale, NJ: Erlbaum.

Arsenio, W. F., \& Lemerise, E. A. (2004). Aggression and moral development: Integrating social information processing and moral domain models. Child Development, 75(4), 987-1002.

Arsenio, W. F., Adams, E., \& Gold, J. (2009). Social information processing, moral reasoning and emotion attributions: Relations with adolescents' reactive and proactive aggression. Child Development, 80(6), 1739-1755.

Asendorpf, J. B., \& van Aken, M. A. G. (2003). Personalityrelationship transaction in adolescence: Core versus surface personality characteristics. Journal of Personality, 71, 629-666.

Barriga, A. Q., \& Gibbs, J. C. (1996). Measuring cognitive distortions in antisocial youth: Development and preliminary validation of the 'how I think' questionnaire. Aggressive Behavior, 22, 333-343.

Barriga, A. Q., Hawkins, M. A., \& Camelia, C. R. T. (2008). Specificity of cognitive distortions to antisocial behaviors. Criminal Behaviour and Mental Health, 18, 104-116.

Berkowitz, L. (1989). Frustration-aggression hypothesis: Examination and reformulation. Psychological Bulletin, 106, 59-73.

Card, N. A., \& Little, T. D. (2006). Proactive and reactive aggression in childhood and adolescence: A meta-analysis of differential relations with psychosocial adjustment. International Journal of Behavioral Development, 30, 466-480.
Caspi, A., \& Shiner, R. L. (2006). Personality development. In W. Damen \& R. Lerner (Eds.), Handbook of child psychology: Social, emotional, and personality development (6th ed., Vol. 3, pp. 300-365). New York: Wiley.

Centraal Bureau voor de Statistiek. (2009). Bevolking; kerncijfers naar diverse kenmerken. http://www.cbs.nl/nl-NL/menu/themas/ bevolking/cijfers/default.htm.

Crick, N. R., \& Dodge, K. A. (1994). A review and reformulation of social information processing mechanisms in children's social adjustment. Psychological Bulletin, 115, 74-101.

Crick, N. R., \& Dodge, K. A. (1996). Social-information processing mechanisms in reactive and proactive aggression. Child Development, 67, 993-1002.

Denissen, J. J. A., Geenen, R., Van Aken, M. A. G., Gosling, S. D., \& Potter, J. (2008). Development and validation of a Dutch translation of the big five inventory (BFI). Journal of Personality Assessment, 90, 152-157.

Dodge, K. A., \& Coie, J. D. (1987). Social-information processing factors in reactive and proactive aggression in children's peer groups. Journal of Personality and Social Psychology, 53(6), $1146-1158$.

Dodge, K. A., \& Rabiner, D. L. (2004). Returning to roots: On social information processing and moral development. Child Development, 75(4), 1003-1008.

Fite, J. E., Goodnight, J. A., Bates, J. E., Dodge, K. E., \& Pettit, G. S. (2008). Adolescent aggression and social cognition in the context of personality: Impulsivity as a moderator of predictions from social information processing. Aggressive Behavior, 34, $511-520$.

Graziano, W. G., Jensen-Campbell, L. A., \& Hair, E. C. (1996). Perceiving interpersonal conflict and reacting to it: The case for agreeableness. Journal of Personality and Social Psychology, $70(4), 820-835$.

Huesmann, L. R. (1988). An information-processing model for the development of aggression. Aggressive Behavior, 14, 13-24.

Huesmann, L. R., Eron, L. D., Guerra, N. G., \& Crawshaw, V. B. (1994). Measuring children's aggression with teachers' predictions of peer-nomination. Psychological Assessment, 6, 329-336.

Huesmann, L. R., \& Guerra, N. G. (1997). Children's normative beliefs about aggression and aggressive behavior. Journal of Personality and Social Psychology, 72, 408-419.

Jensen-Campbell, L. A., Rosselli, M., Workman, K. A., Santisi, M., Rios, J. D., \& Bojan, D. (2002). Agreeableness, conscientiousness, and effortful control processes. Journal of Research in Personality, 36, 476-489.

Jensen-Campbell, L. A., Knack, J. N., Waldrip, A. M., \& Campbell, S. D. (2007). Do big five personality traits associated with selfcontrol influence the regulation of anger and aggression? Journal of Research in Personality, 41, 403-424.

Liau, A. K., Barriga, A. Q., \& Gibbs, J. C. (1998). Relations between self-serving cognitive distortions and overt versus covert antisocial behavior in adolescents. Aggressive Behavior, 24, 335-346.

Loeber, R., \& Schmaling, K. B. (1985). Empirical evidence for overt and covert patterns of antisocial conduct problems: A metaanalysis. Journal of Abnormal Child Psychology, 13(2), 337-352.

Marsee, M. A., \& Frick, P. J. (2007). Exploring the cognitive and emotional correlates to proactive and reactive aggression in a sample of detained girls. Journal of Abnormal Child Psychology, 35, 969-981.

Meier, B. P., \& Robinson, M. D. (2004). Does quick to blame mean quick to anger? The role of agreeableness in dissociating blame and anger. Personality and Social Psychology Bulletin, 30, $856-867$.

Nas, C. N., Brugman, D., \& Koops, W. (2008). Measuring self-serving cognitive distortions with the 'how I think' 
questionnaire. European Journal of Psychological Assessment, 24(3), 181-189.

Palmer, E. J. (2003). An overview of the relationship between moral reasoning and offending. Australian Psychologist, 38(3), $165-174$.

Palmer, E. J. (2005). The relationship between moral reasoning and aggression, and the implications for practice. Psychology Crime and Law, 11(4), 353-361.

Peets, K., Hodges, E. V. E., \& Salmivalli, C. (2011). Actualization of social cognitions into aggressive behavior toward disliked targets. Social Development, 20(2), 233-250.

Polman, H., Orobio de Castro, B., Koops, W., Van Boxtel, H. W., \& Merk, W. (2007). Meta analysis of the distinction between reactive and proactive aggression in children and adolescents. Journal of Abnormal Child Psychology, 35, 522-535.

Polman, H., Orobio de Castro, B., Thomaes, S. E., \& Van Aken, M. A. G. (2008). New directions in measuring proactive and reactive aggression: Validation of a teacher questionnaire. Journal of Abnormal Child Psychology, 37, 183-193.
Sim, T. N., \& Koh, S. F. (2003). A domain conceptualization of adolescent susceptibility to peer pressure. Journal of Research on Adolescence, 13, 57-80.

Smithmyer, C. M., Hubbard, J. A., \& Simons, R. F. (2000). Proactive and reactive aggression in delinquent adolescents: Relations to aggression outcome expectancies. Journal of Clinical Child Psychology, 29(1), 86-93.

Tabachnick, B. G., \& Fidell, L. S. (2007). Using multivariate statistics (5th ed.). Boston: Allyn and Bacon.

van der Velden, F., Brugman, D., Boom, J., \& Koops, W. (2010). Moral cognitive processes explaining antisocial behavior in young adolescents. International Journal of Behavioral Development, 34(4), 292-301.

Vitaro, F., Gendreau, P. L., Tremblay, R. E., \& Oligny, P. (1998). Reactive and proactive aggression differentially predict later conduct problems. Journal of Child Psychology and Psychiatry, 39, 377-385.

Weiss, B., Harris, V., \& Catron, T. (2002). Development and validation of the peer-report measure of internalizing and externalizing behavior. Journal of Abnormal Child Psychology, 30, 258-294. 